\title{
CARACTERIZAÇÃO QUALI-QUANTITATIVA DE RESÍDUOS SÓLIDOS INDUSTRIAIS: ESTUDO DE CASO DE UMA LINHA DE PRODUÇÃO DA EMPRESA FLORESTAL NORTE LTDA
}

\section{CHARACTERIZATION QUALITATIVE AND QUANTITATIVE INDUSTRIAL SOLID WASTE: A CASE STUDY OF A LINE NORTH FOREST PRODUCTION COMPANY LTDA}

\author{
Jakeline Oliveira Evangelista ${ }^{1}$; Glauber Epifanio Loureiro ${ }^{2}$; Jonathas Castanha Bezerra ${ }^{3}$; \\ ${ }^{1}$ Universidade do Estado do Pará (UEPA) - Belém - PA - Brasil \\ jaakeline95@hotmail.com \\ ${ }^{2}$ Universidade do Estado do Pará (UEPA) - Belém - PA - Brasil \\ epfanio@uepa.br \\ ${ }^{3}$ Universidade do Estado do Pará (UEPA) - Belém - PA - Brasil \\ jonathascastanha@yahoo.com.br
}

\begin{abstract}
Resumo
A necessidade de poupar matéria-prima e recursos, conservar energia e preservar o meio ambiente torna fundamental uma gestão eficiente sobre os resíduos sólidos a partir de varias ações, procedimentos e comportamentos que possam minimizar os impactos ligados à produção e destinação do lixo sobre o meio ambiente. Por ser considerado como de alto risco à saúde humana e ao meio ambiente, deve-se uma atenção maior aos resíduos gerados em indústrias (RI). O escopo do presente trabalho foi analisar as características qualiquantitativas dos resíduos sólidos gerados na linha de produção na empresa Florestal Norte LTDA. No fim do estudo, observou-se que menos de $3 \%$ dos resíduos gerados mensalmente é destinado ao aterro sanitário, este aspecto positivo, mostra que essas áreas são adequadas para abrigar sistemas de destinação final do lixo, provocando diminuição residual do (RI). Em virtude do que foi mencionado, entende-se que cerca de $97 \%$ dos (RI) desta empresa são passiveis de reciclagem.
\end{abstract}

Palavras-chave: resíduos sólidos; gestão de resíduos; reciclagem.

\section{Introdução}

O ser humano, no desenvolvimento de várias atividades no dia-a-dia, produz e descarta grande quantidade de resíduos. Para estas atividades, contou-se com o avanço tecnológico e industrial no mundo, onde surgiram produtos e bens de consumo sofisticados, consolidando-se a enorme capacidade do homem para explorar os recursos naturais (PEREIRA NETO, 2007). 
Em meio aos resíduos gerados encontram-se alguns que, devido à origem ou as características físicas, químicas e/ou biológicas, oferecem maior risco à qualidade da vida humana e ao meio ambiente.

Devido às características os resíduos gerados em indústrias, são considerados como de grande risco à qualidade de vida humana e ao meio ambiente. Os danos causados por estes resíduos são muitas vezes irreparáveis, pois atingem direta ou indiretamente os recursos naturais onde está localizado o empreendimento e a população circunvizinha. Devido a este fato tem-se estimulado diversas maneiras de minimizar os efeitos causados pelos resíduos gerados nas indústrias.

No mais, com respaldo legal e experiências de outras áreas, estão sendo implantados planos de gerenciamento de resíduos sólidos industriais como proposta na mitigação dos impactos gerados pelos resíduos sólidos nas indústrias (OLIVEIRA, 2006).

De acordo com a norma NBR, 10004/2004, são considerados Resíduos Sólidos (RS) os resíduos em estado sólido e semi-sólido, incluindo os lodos provenientes de sistemas de tratamento de água, aqueles gerados em equipamentos e instalações de controle de poluição, bem como determinados líquidos cujas particularidades tornem inevitável o seu tratamento na rede pública de esgotos ou corpos de água, ou exijam para isso soluções técnicas e economicamente inevitáveis em face à melhor tecnologia disponível.

O gerenciamento de resíduos sólidos é considerado um dos assuntos mais significantes nas questões ambientais, em vista dos aspectos técnicos envolvidos e ambientais decorrentes. É um processo que aponta e descreve as ações relativas ao manejo dos resíduos sólidos no âmbito dos estabelecimentos, contemplando a segregação na origem, acondicionamento, armazenamento, transporte, minimização, reutilização, reciclagem, tratamento e disposição final (PIMENTA \& JUNIOR, 2006).

A indústria de produtos florestais apresenta como aspecto ambiental crítico, a geração de resíduos sólidos, o qual dependendo de seu gerenciamento podem ocasionar impactos significativos ao meio ambiente. Dentre a geração de resíduos sólidos, tem-se os resíduos de processo que correspondem a matéria prima de beneficiamento e resíduos oriundos de insumos. Todos estes apresentam elevado potencial de reciclagem e programas de responsabilidade social.

Para tanto, faz-se necessário, a caracterização quantitativa e qualitativa de modo a dimensionar os coletores, dimensionar abrigo temporário e definitivo, bem como conhecer a qualidade de resíduos que possam ser reaproveitados ou reciclados. Resultando em menos 
resíduo a ser tratado ou disposto, isto é minimizando a quantidade enviada para aterros (NETA, 2002).

Logo, este estudo tem como objetivo caracterizar os resíduos industriais para fornecer subsídios a um plano de gerenciamento de resíduos sólidos industriais na linha de produção de uma empresa florestal.

\section{Revisão bibliográfica}

A Associação Brasileira de Normas Técnicas (ABNT, 2004), denomina como resíduo sólido, os restos de atividades humanas, considerados pelos geradores como inúteis, indesejáveis ou descartáveis. Normalmente, apresentam-se sob estado sólido, semi-sólido ou semi-líquido com conteúdo líquido insuficiente para que este possa fluir livremente.

De acordo com Monteiro (2001), resíduo sólido ou simplesmente "lixo" é todo material sólido ou semi-sólido indesejável e que necessita ser removido por ter sido considerado inútil por quem o descarta em qualquer recipiente destinado a este ato.

A ABNT editou um conjunto de normas para padronizar, a nível nacional, a classificação dos resíduos sólidos. Uma delas é a norma NBR 10.004/2004 que diz respeito à classificação dos resíduos sólidos e aponta os seus riscos potenciais ao meio ambiente

Segundo ABNT NBR 10.004/2004, tem-se:

- RESÍDUOS PERIGOSOS - CLASSE I: são aqueles que em função de suas características intrínsecas de inflamabilidade, corrosividade, reatividade, toxicidade ou patogenicidade, apresentam risco à saúde pública através do aumento da mortalidade ou da morbidade, ou ainda provocam efeitos adversos ao meio ambiente quando manuseados ou dispostos de forma inadequada;

- RESÍDUOS NÃO PERIGOSOS - CLASSE II-A: são resíduos não inertes que podem apresentar características de combustibilidade, biodegradabilidade ou solubilidade, porém, não se enquadram como resíduo classe I ou II-B;

- RESÍDUOS NÃO PERIGOSOS - CLASSE II-B: são aqueles que por suas características intrínsecas, não oferecem risco à saúde e ao meio ambiente, e que, quando amostrados de forma representativa, segundo a norma NBR 10.007/2004 (ABNT), e submetidos a um contato estático ou dinâmico com água destilada ou deionizada, a temperatura ambiente, conforme teste de solubilização segundo a norma 10.006/2004 (ABNT), não tiverem nenhum de seus constituintes solubilizados a concentrações superiores 
aos padrões de potabilidade da água, conforme listagem $\mathrm{n}^{\circ} 8$ (anexo H da NBR 10.004), excetuando-se os padrões de aspecto, cor, turbidez e sabor.

Segundo Rocca (1993) são considerados Resíduos Sólidos Industriais (RSI) os resíduos em estado sólido e semi-sólido que resultem da atividade industrial, incluindo-se os lodos provenientes das instalações de tratamento de águas residuárias, aqueles gerados equipamentos de controle de poluição, bem como determinados líquidos cujas particularidades tornem inviável o seu lançamento na rede pública e esgotos ou corpos d'água, ou exigem, para isso, soluções economicamente inviáveis, em face da melhor tecnologia disponível.

Além de sua classificação segundo a ABNT NBR 10.004/2004, podem ser classificados quanto a sua geração e características.

a) Quanto à geração

De acordo com a Comisión de Producción Limpia (CPL) (2005) os resíduos sólidos industriais podem ser classificados de acordo com sua geração em:

- Resíduos finais de processo: Resultam das operações que em não são empregadas completamente matérias primas ou daquelas operações onde são gerados resíduos não utilizáveis no processo.

- Produtos rejeitados: Provém dos processos de controle de qualidade, no produto ou matéria prima que pode ser rejeitado quando se encontra fora de especificação.

Embalagem: Todos os envases, vasilhames ou envoltórios de matérias primas e insumos descartados, uma vez que cumpriram seus objetivos de transporte e distribuição de produtos.

- Fim de vida útil: Todo produto que após seu prazo de validade não pode ser utilizado para o que foi produzido.

b) Quanto a sua característica

De acordo com a Diretriz-1310 da Federação Estadual de Engenharia do Meio Ambiente (FEEMA) (2004), os resíduos industriais podem ser classificados como:

- Resíduos industriais perigosos: São todos os resíduos sólidos, semissólidos e os líquidos não passiveis de tratamento convencional, resultantes da atividade industrial e do tratamento de seus efluentes líquidos e gasosos que, por suas características, apresentem periculosidade efetiva ou potencial à saúde humana e ao meio ambiente, requerendo cuidados especiais quanto ao seu gerenciamento; e

- Resíduos industriais comuns: São todos os resíduos industriais sólidos e semissólidos com características semelhantes às dos resíduos sólidos urbanos. 


\section{Materiais e métodos}

Foi realizado estudo na linha de produção de Piso de uma Empresa aqui denominada "Florestal Norte LTDA", onde, segundo dados da empresa, a geração de resíduos é diária, porém, não há controle e mensuração dos mesmos. Entretanto, o setor contribui significativamente na geração de resíduos perigosos e inorgânicos, devido características rotineiras de produção.

O método de pesquisa corresponde ao diagnóstico ambiental, para a avaliação dos resíduos sólidos gerados pelo processo como requisito preliminar ao gerenciamento. Os diagnósticos seguem uma metodologia de investigação, por meio de uma coleta de dados ordenada, de forma que o conjunto observado conduza a conclusões. Para a formulação do diagnóstico, utilizou-se a combinação de técnicas como: constatação in locu acerca das condições de infraestrutura, materiais de apoio, condições de trabalho, logística interna, dados acerca do manejo e disposição dos resíduos gerados, registros fotográficos.

Em seguida, os resíduos sólidos provenientes do setor foram qualificados, segundo enquadramento da NBR 10.004/2004 e identificados ilustrados na Tabela 1.

Tabela 1- Relação dos resíduos quantificados e seu mecanismo de identificação.

\begin{tabular}{cc}
\hline Resíduos & Identificação (Conama, $\mathbf{n} \mathbf{0} 275 / \mathbf{0 1})$ \\
\hline Papel & Azul \\
Plásticos & Vermelho \\
Perigosos & Laranja \\
Outros & Cinza \\
Geral & Cinza rachurado \\
\hline
\end{tabular}

Fonte: Autoria própria (2014).

$\mathrm{Na}$ quantificação foi considerada nomenclatura que compreende os seguintes tipos de resíduos oriundos da linha de produção de Piso Maciço, selecionados para serem quantificados, onde os mesmos foram agrupados para facilitar a segregação e gerenciamento conforme CONAMA (2001):

a) Grupo Papel

- Subgrupo papelão; e

- Subgrupo rolo de papelão.

Grupo Plástico

- Subgrupo plástico Polietileno;

- Subgrupo plástico PET e PP - Fita PET AAR11, verde e Fita PET 19 mm, e Fita PP $10 \mathrm{~mm}$.

b) Grupo Metal 
- Subgrupo metal - fita metálica e sobra de peças;

c) Grupo Perigosos

- Subgrupo plástico contaminado - galões de óleo lubrificante, hidráulico, desengraxante, querosene e demais resíduos plásticos contaminados exceto metálicos.

- Subgrupo metal contaminado - vasilhame de aço contendo óleo lubrificante, querosene, tintas e anti-corrosivos.

d) Grupo Outros:

Subgrupo - material com potencial de reutilização e/ou reciclagem interna ou externa por intermédio de procedimento tecnológico.

e) Grupo Geral:

- Subgrupo Geral - material sem potencial de reutilização interna ou externa como resíduo de varrição de fábrica.

O processo de quantificação decorreu, mediante coleta constituídas pela geração diária durante 8 horas de trabalho, que se estendeu no período de 35 dias úteis consecutivos, 7 semanas, somente nos 5 dias úteis da semana, bem como dos materiais necessários demonstrados nas Figuras 1 à Figura 3.

Figura 1 - Ilustração do compressor manual, para diminuir os vazios dos plásticos e estimar o volume no recipiente de volume conhecido.

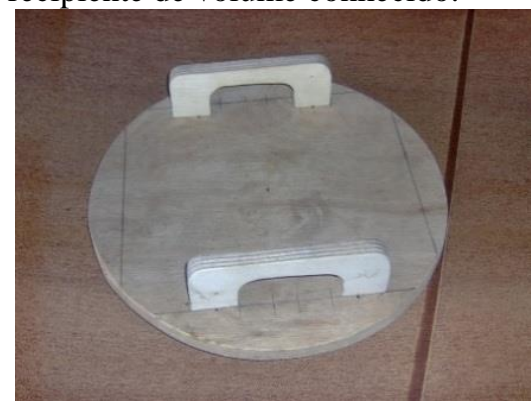

Fonte: Autoria própria (2014).

Figura 2 - Ilustração da balança eletrônica com estrado, capacidade máxima para 2 toneladas, Modelo ULP, Classe de exatidão III, tara $100 \%$.

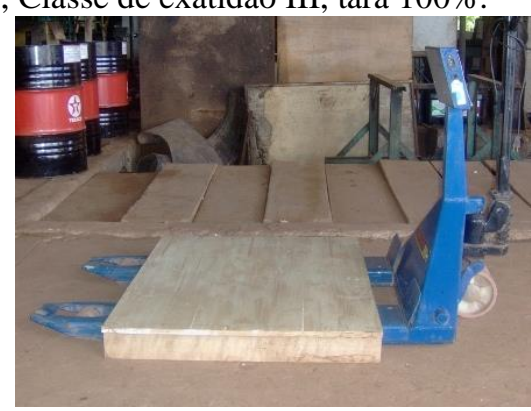

Fonte: Autoria própria (2014). 
Figura 3 - Ilustração dos recipientes de capacidade conhecida perfazendo no conjunto cerca de $100 \mathrm{~L}$ ou $0,1 \mathrm{~m}^{3}$, para determinação de massa volumétrica.

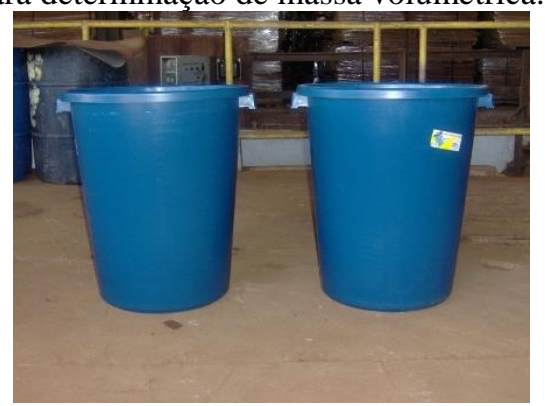

Fonte: Autoria própria (2014).

Após a obtenção das amostras, os dados foram tratados em bases aritméticas para estimar e projetar a frequência de geração de resíduos sólidos no setor, conforme a equação 1: $V_{x}=\left[\frac{S}{5 \times N}\right] \times Z$

[1]

Fonte: Adaptado de SECRETARIA REGIONAL DO AMBIENTE, 1989.

Onde $=$ Quantidade de resíduo numa frequência diária, semanal, mensal ou anual; = Soma dos resíduos pesados nas semanas; = Número de semanas de pesagem; = 1; para frequência diária; = 5; para frequência semanal; = 20; para frequência mensal; e = 240; para frequência anual.

Para obtenção do volume de RSI gerados semanalmente para determinação da capacidade dos coletores, adotou-se a equação 2 (SBRT, 2006):

$V \frac{M}{\mu_{a p}} \times 1000$

[2]

Fonte: SBRT, 2006

Onde: $V=$ Volume do coletor; $M=$ Massa do resíduo de sua geração semanal $(\mathrm{Kg})$; e $\mu_{a p}=$ Densidade aparente $\left(\mathrm{Kg} / \mathrm{m}^{3}\right)$.

Segundo SBRT (2006) a massa pode ser obtida com o uso de uma balança. O objetivo é verificar a densidade aparente de acordo com os resíduos nos coletores considerando a presença de vazios dos mesmos acondicionados no recipiente de volume conhecido, isto é, no presente caso os contêineres já existentes na segregação e acondicionamento pertencentes à linha de produção estudada.

Dessa forma, o cálculo da densidade aparente foi calculado com o emprego da (equação 3), que demonstra a relação da massa "em quilogramas" dos subgrupos de resíduos 
que estavam nos coletores segregados em um dia do circuito de pesagem pelo seu volume aparente $\left(\mathrm{em} \mathrm{Kg} / \mathrm{m}^{3}\right)$ dado pelo volume do coletor quando estava completamente cheio.

$\mu_{a p}=\frac{M}{V_{a p}}$

[3]

Fonte: SBRT, 2006

Onde: $\mu_{a p}=$ Densidade aparente $\left(\mathrm{Kg} / \mathrm{m}^{3}\right) ; V_{a p}=$ Volume aparente dado pelo volume do coletor $\left(\mathrm{m}^{3}\right)$; e $M=$ Massa do resíduo em um dia do circuito de pesagem $(\mathrm{Kg})$.

\section{Resultados e discussões}

Os resíduos sólidos são gerados de acordo com o processo produtivo e nas fontes de geração foram realizados a sua identificação e causas de geração para subsidiar formas de minimização para um futuro plano de gerenciamento conforme Quadro 1.

Quadro 1 - Unidades de geração de resíduos e sua causa de geração.

\begin{tabular}{|c|c|c|}
\hline Fonte geração & Causa de geração & Identificação de resíduo \\
\hline \multicolumn{3}{|l|}{ Linha de Produção: Piso } \\
\hline Plaina 2 Faces & $\begin{array}{l}\text { - Ação de desempacotar a } \\
\text { madeira proveniente do estoque. } \\
\text { - Ação de manutenção } \\
\text { preventiva e corretiva da } \\
\text { máquina com produtos derivados } \\
\text { de petróleo. }\end{array}$ & $\begin{array}{lr}\text { Recipiente de aço contaminado, } \\
\text { Vasilhame de } \\
\text { contaminado, } \\
\text { contaminados. }\end{array}$ \\
\hline Destopadeiras & $\begin{array}{l}\text { - Ação de manutenção } \\
\text { preventiva e corretiva da } \\
\text { máquina com produtos derivados } \\
\text { de petróleo. }\end{array}$ & $\begin{array}{l}\text { Recipiente de plástico } \\
\text { contaminado. }\end{array}$ \\
\hline Refiladeiras & $\begin{array}{l}\text { - Ação de manutenção } \\
\text { preventiva e corretiva da } \\
\text { máquina com produtos derivados } \\
\text { de petróleo. } \\
\text { - Engradeamento de fasquil para } \\
\text { ser direcionado até a caldeira. }\end{array}$ & $\begin{array}{l}\text { Recipiente de aço contaminado, } \\
\text { vasilhame de plástico } \\
\text { contaminado, } \\
\text { contaminados e fita metálica. }\end{array}$ \\
\hline Otimizadora & $\begin{array}{l}\text { - Ação de manutenção } \\
\text { preventiva e corretiva da } \\
\text { máquina com produtos derivados } \\
\text { de petróleo. } \\
\text { - Classificação visual e marcação } \\
\text { com giz. }\end{array}$ & $\begin{array}{l}\text { Papel, Recipiente de aço } \\
\text { contaminado, Vasilhame de } \\
\text { plástico contaminado, panos } \\
\text { contaminados. }\end{array}$ \\
\hline Moldureira & $\begin{array}{l}\text { - Ação de manutenção } \\
\text { preventiva e corretiva da } \\
\text { máquina com produtos derivados } \\
\text { de petróleo. }\end{array}$ & $\begin{array}{l}\text { Recipiente de aço contaminado, } \\
\text { Vasilhame de plástico } \\
\text { contaminado. }\end{array}$ \\
\hline
\end{tabular}




\begin{tabular}{|c|c|c|}
\hline Esteira & $\begin{array}{l}\text { - Ação de manutenção } \\
\text { preventiva e corretiva com } \\
\text { utilização de graxa líquida. }\end{array}$ & Vasilhame aço contaminado. \\
\hline Área de Empacotamento & - Embalagem do produto final & $\begin{array}{l}\text { Fita poliéster AAR11, lona } \\
\text { plástica e caixa e rolo de papelão. }\end{array}$ \\
\hline Área Geral & $\begin{array}{l}\text { - Varrição, pinturas de } \\
\text { manutenção na fábrica, limpeza } \\
\text { do setor e processos normais de } \\
\text { trabalho como transição de } \\
\text { pessoas e máquinas. } \\
\text { - Danificação dos tubos } \\
\text { exaustores por atrito com resíduo } \\
\text { de madeira, (pó e fasquil). }\end{array}$ & $\begin{array}{l}\text { Resíduos de varrição, tubo } \\
\text { exaustor, EPI contaminado e não } \\
\text { contaminado. }\end{array}$ \\
\hline
\end{tabular}

Fonte: Autoria própria (2014).

Pelo diagnóstico realizado os resíduos gerados no processo foram acondicionados em tambores metálicos improvisados, ou lançados ao chão da área produtiva conforme mostram as Figura $4 \mathrm{a}, 4 \mathrm{~b}$ e $4 \mathrm{c}$.

Apesar de haver um sistema de coleta seletiva não documentada, sem o símbolo padrão de reciclagem (Fig. 4a) a quantidade dos mesmos é insuficiente para receber os resíduos gerados pelo setor, fato comprovado em prática, quando os mesmos são visualizados ao chão (fig. 4c), onde o fluxo de movimentação humana e de máquinas é intenso, além de possibilitar um aspecto visual desagradável para colaboradores e clientes.

De acordo com a Figura 4b, notou-se que os funcionários não separam corretamente os resíduos de acordo com suas características. Tal fato dificulta o processo de comercialização dos mesmos e possibilita perda de tempo no trabalho realizado pelo funcionário para estar separando cada tipo de resíduos depois que os mesmos se encontram completamente misturados nos contendores. Portanto, a segregação não segue a classificação de acordo com a NBR-11174/90 (resíduos classe II-A e II-B) e NBR-12235/92 (resíduos classe I) em grupos ou categorias de resíduos.

\subsection{Caracterização qualitativa}

A classificação baseia-se nas características dos resíduos, se reconhecidos como perigosos, ou quanto à concentração de poluentes. Também como forma de normatizar a identificação e classificação de resíduos com a nomenclatura mundial, tomou-se como base a Tabela de Códigos de resíduos da União Européia adotada pelo órgão Ambiental Federal (CONAMA, 2002). Para a classificação dos RSI, não se precisou recorrer a testes de lixiviação ou solubilização de resíduos, pois os resíduos já se encontravam listados em anexos 
da Norma ABNT NBR 10.004 ou dentro das características de substâncias corrosivas, inflamáveis e/ou tóxicas. Então, de forma geral os resíduos foram classificados conforme disposto no Quadro 2.

Quadro 2 - Qualificação técnica dos resíduos gerados pelo setor

\begin{tabular}{|c|c|c|c|}
\hline Cód. & Descrição & $\begin{array}{c}\text { Classificação } \\
\text { (ABNT 10.004/2004) }\end{array}$ & Composição \\
\hline A003 & Resíduo de varrição de fábrica. & Classe II-A & Pó de serra + silicáticos. \\
\hline A004 & Fita Metálica. & Classe II-A & Aço. \\
\hline A006 & Papelão. & Classe II-A & Fibras de celulose. \\
\hline A207 & Fita Plástica. & Classe II-A & $\begin{array}{l}\text { Polipropileno }(\mathrm{PP}) \text { e } \\
\text { Politereftalato de etila (PET). }\end{array}$ \\
\hline A207 & Plástico. & Classe II-A & Poliestireno (PE). \\
\hline A208 & Tubo para exaustão & Classe II-B & Plástico de poliuretano \\
\hline A010 & Tecido não contaminado & Classe II-A & Brim \\
\hline D001 & Vasilhame de solvente contaminado. & Classe I & Aço + derivado de petróleo. \\
\hline D001 & $\begin{array}{l}\text { Vasilhame de anticorrosivo } \\
\text { contaminado. }\end{array}$ & Classe I & Aço + derivado de petróleo. \\
\hline D001 & $\begin{array}{l}\text { Vasilhame de óleo lubrificante } \\
\text { contaminado. }\end{array}$ & Classe I & $\begin{array}{l}\text { Plástico }+ \text { derivado de } \\
\text { petróleo. }\end{array}$ \\
\hline D001 & Vasilhame de querosene contaminado. & Classe I & Aço + derivado de petróleo. \\
\hline D001 & Vasilhame de graxa líquida contaminada. & Classe I & Aço + derivado de petróleo. \\
\hline F104 & Vasilhame de tinta contaminado & Classe I & Aço + derivado de petróleo \\
\hline F104 & Vasilhame de adesivo contaminado & Classe I & Aço + derivado de petróleo \\
\hline $\mathrm{I} 134$ & $\begin{array}{l}\text { Vasilhame de Fluido para freio } \\
\text { contaminado }\end{array}$ & Classe I & Aço + derivado de petróleo \\
\hline
\end{tabular}

Fonte: Autoria própria (2014).

Nota-se que os RSI identificados na linha de produção pesquisada apresentam em sua maioria características semelhantes de resíduos urbanos, ou seja, formado por resíduos industriais de modo geral comuns, do ponto de vista usual.

Corrobora-se pela análise da Figura 4, que os resíduos identificados como não inertes "Classe II-A" representam mais de $40 \%$ dos RSI identificados, isto é, possuindo características biodegradáveis, solubilidade em água e combustibilidade. O que demonstra em sua maioria o seu potencial de ser um produto reciclável ou reutilizável, a Figura 5 demonstra o percentual do RSI identificados de acordo com a ABNT NBR 10.004.

Figura 5 - Ilustração do percentual de RSI identificados de acordo com a ABNT NBR 10.004 


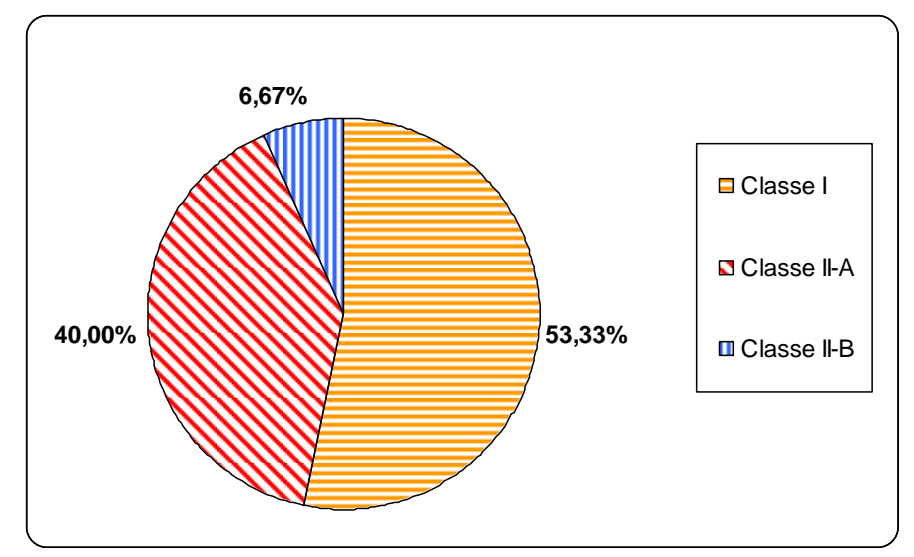

Fonte: Autoria própria (2014).

A identificação de um produto perigoso nem sempre implica em resíduo sólido perigoso. No entanto, os rótulos dos produtos identificados indicam o perigo ao meio ambiente, saúde humana e sua concentração de composição do constituinte. Dessa forma estes foram enquadrados de acordo com a classificação da ABNT NBR 10.004, mais precisamente "Classe I".

Vale ressaltar que apesar da embalagem possuir características potenciais de reciclagem, devido sua constituição química, a mesma em contato com uma substância perigosa, passa a estar contaminada. Dessa forma é considerado resíduo perigoso como identificado pelos códigos D001, F104, I134 no Quadro 3.

De acordo com a Figura 5, os resíduos sólidos perigosos "Classe I" identificados apresentam uma situação preocupante, pois apesar de representarem mais de 50\% dos RSI identificados no setor, na caracterização qualitativa, estes indicam um custo adicional elevado no gerenciamento de RSI, devido o seu tratamento antes da disposição final.

Os resíduos sólidos inertes "Classe II-B" representam a minoria. As características do material indicam a sua difícil decomposição no meio ambiente, isto é, não apresentando características de resíduo perigoso, mas podem afetar indiretamente, o ecossistema, quando dispostos inadequadamente, podendo ocasionar poluição visual e ambiente propício para criação de vetores.

\subsection{Caracterização quantitativa}

Em consonância com CONAMA n 313/2002, a identificação da frequência de geração torna-se fundamental na engenharia de resíduos sólidos, haja vista que decisões de gestão e gerenciamento devem ser tomadas conscientemente, por meio do levantamento de 
indicadores e do controle adequado na geração de resíduos, sejam eles perigosos ou não, de forma a corrigir os problemas existentes e principalmente antecipar soluções antes que os problemas possam surgir. Um dos exemplos que podem ser citados, é o caso desta linha de produção qualidade ambiental, pode ser mencionado os desperdícios que ocorrem, tanto no uso da matéria-prima, quanto na utilização de insumos envolvidos na linha de produção.

Em especial, deve ser dada atenção aos pontos críticos, ou seja, que geram maior quantidade de resíduos e suas características de comercialização, dentro de um sistema de reciclagem, além do controle dos processos produtivos que apresentam baixa eficiência, gerando resíduos a mais do que estimado.

A geração de resíduos de plástico e papel (Figura 6) correspondem juntos a quase $90 \%$ da geração do setor estudado, onde a comercialização dos mesmos ocorre amplamente na região. Porém a quantidade dos demais resíduos gerados é relativamente pequena, no entanto atenção especial deve ser dada aos perigosos, que equivalem $1,57 \%$ na geração, devido suas características inflamáveis e tóxicas merecem atenção tanto do ponto de vista técnico e legal. Também o Subgrupo de Fita PET e PP (Figura 7), pois não possuem valor direto na comercialização entre as empresas de reciclagem da região.

Figura 6 - Ilustração do percentual de geração de resíduos no mês.

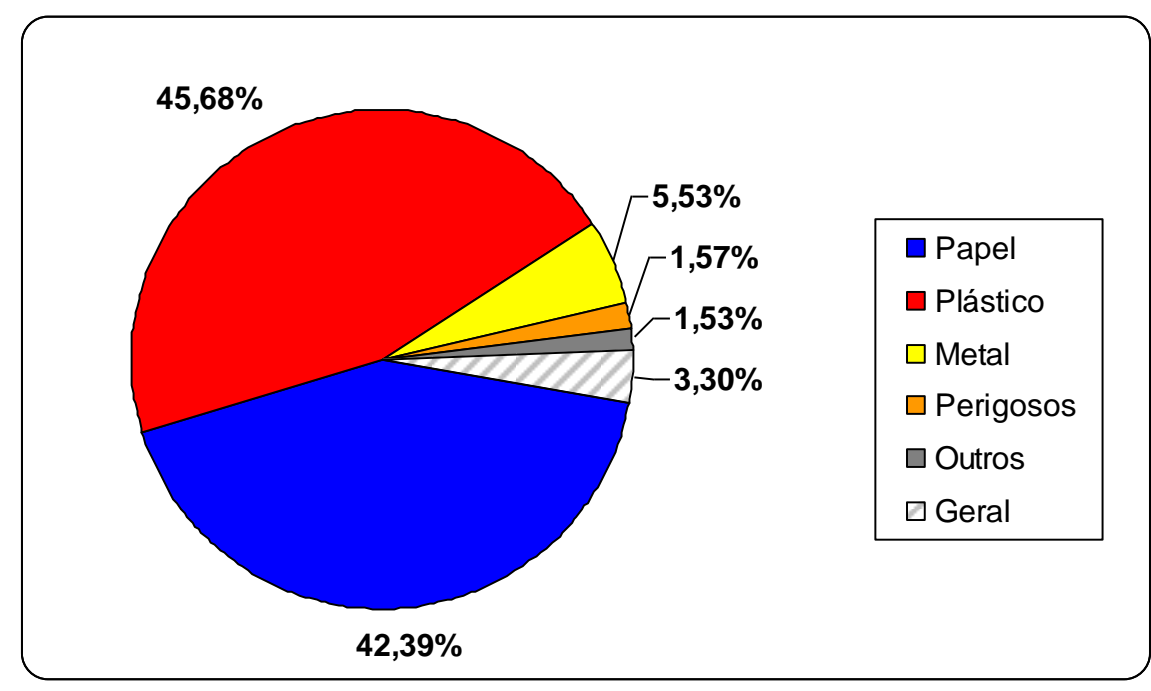

Fonte: Autoria própria (2014).

De acordo com as Figuras 6 e 7, pode-se afirmar que a quantidade elevada na geração do Grupo Papel está associada em mais de 50\% ao subgrupo papelão. O Rolo de papelão possui uma geração mensal de $99.43 \mathrm{Kg}$, sendo que, cada Rolo de papelão com 1,2 metros de comprimento, apresenta $3 \mathrm{Kg}$, isto é, um total de aproximadamente 33 rolos de papelão. Este 
valor está relacionado ao uso intenso do plástico Filme Stretch para envolvimento do produto acabado, visando a exportação, onde o Rolo de Papelão é seu suporte.

O Grupo Plástico representa, de acordo com as Figuras 6 e 7 mais de 50\% de geração mensal de RSI. Este valor em potencial deve-se ao fato do uso do Plástico PE para envolvimento das peças de madeira para minimizar a ação da umidade na estocagem e entrada da linha de produção quanto na exportação do produto. Estes processos têm uma geração para este Subgrupo de 34,50\%. Já o subgrupo de Fitas Plásticas PET e PP, estão associados ao arqueamento manual e automático, respectivamente na linha de produção, perfazendo assim uma geração mensal equivalente a $11,19 \%$.

O metal é representado pelo uso de fita metálica, sua geração tem diminuído durante o circuito de pesagem pelo fato de sua substituição pela Fita PET que apresenta mesma função, porém um custo menor. As fitas metálicas presentes em sua maioria são oriundas de grades de madeiras, provenientes da serraria de terceiros.

A geração de resíduos perigosos é baixa $(1,57 \%)$ se comparada com os demais grupos de resíduos. Isto apresenta uma contradição se comparada com o percentual de resíduos identificados como perigosos de acordo com a Figura 6.

De acordo com a Figura 6 e 7 a geração de resíduos do Grupo "Outros" se apresenta dentro dos padrões, onde a geração de tubo exaustor está associada à produção, manutenção e qualidade do material, onde pode-se propor a compra de um tubo mais resistente e avaliar os custos, para se tratar os materiais que se danificam com maior facilidade ou adquirir produtos mais resistentes, onde custos com tratamento e investimento na compra de materiais, não estão no bojo da abordagem no presente trabalho.

A geração de resíduos do Grupo Geral se apresenta elevada com um percentual um pouco maior que 50\% em comparação com o Grupo Outros, lembrando que o Grupo Geral é apenas formado por resíduo de varrição de fábrica. A sua geração está associado ao fato das vias de circulação não ser pavimentada. Aliado a isso o trânsito de máquinas e pessoas dentre a linha de produção pesquisada contribui para o acúmulo de resíduo de varrição de fábrica, de composição normal de (areia e pó de madeira). A linha de produção é varrida todos os dias antes e após o término das atividades diárias. 
Figura 7 - Ilustração do percentual de geração mensal referente aos subgrupos de resíduos

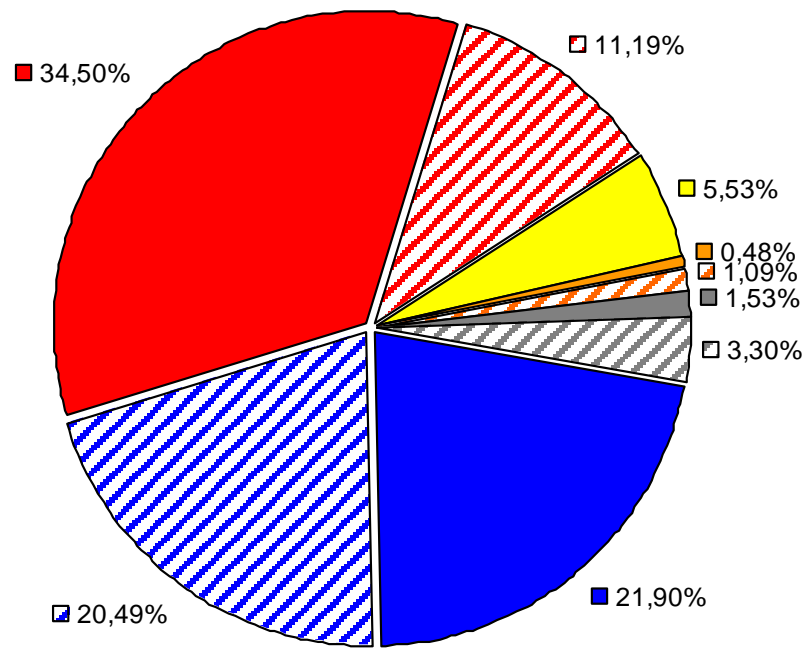

Papelão

$\square$ Rolo papelão

口 Plástico PE

๑ Fitas Plásticas PP e PET

$\square$ Metal

$\square$ Perigoso Metálico

๑ Perigoso Plástico

$\square$ Outros

$\square$ Geral

Fonte: Autoria própria (2014).

Figura 8 - Ilustração do potencial de reciclagem pela característica dos resíduos gerados.

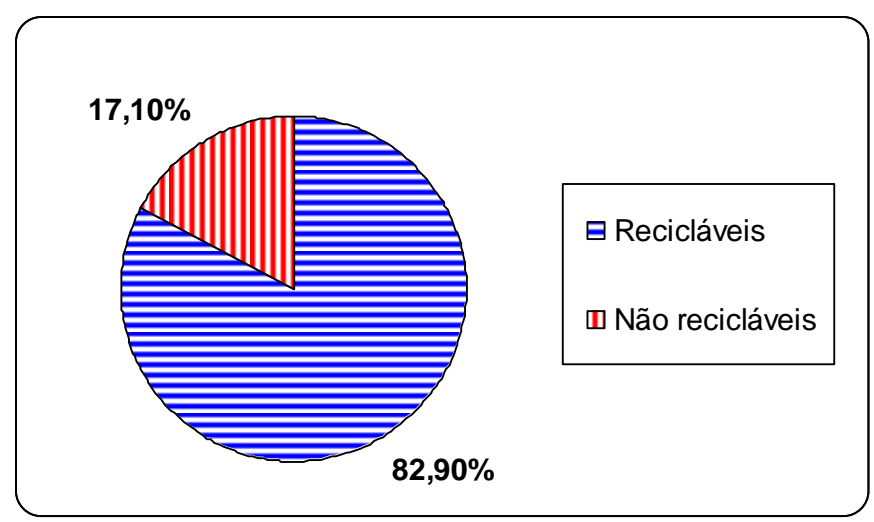

Fonte: Autoria própria (2014).

Logo, analisando a Figura 8, nota-se que, apesar da quantidade de resíduo de Classe I tenha sido elevada (> 50\%), não condiz com a realidade de quantidade de resíduos gerados em quilogramas de acordo com a classificação da ABNT NBR 10.004/2004 pois se apresenta ínfima (< 2\%). Essa contradição é devido à diversidade de diferentes vasilhames contaminados que apesar de vazios, contém ainda a substância contaminante e por isso são considerados resíduos perigosos. Diferentemente dos Resíduos perigosos, os resíduos enquadrados como Classe II-A representam uma quantidade significativa de mais de $90 \%$, corroborando sua identificação em 40\%. O resíduo Classe II-B, é representado apenas pelo tubo exaustor. Com identificação menor que $10 \%$ e quantidade ínfima de geração $(<1 \%)$, a 
Figura 9 ilustra a comparação entre a identificação e quantificação de acordo com a ABNT NBR 10.004/04.

Figura 9 - Ilustração da comparação entre a identificação e quantificação de acordo com a ABNT NBR $10.004 / 04$.

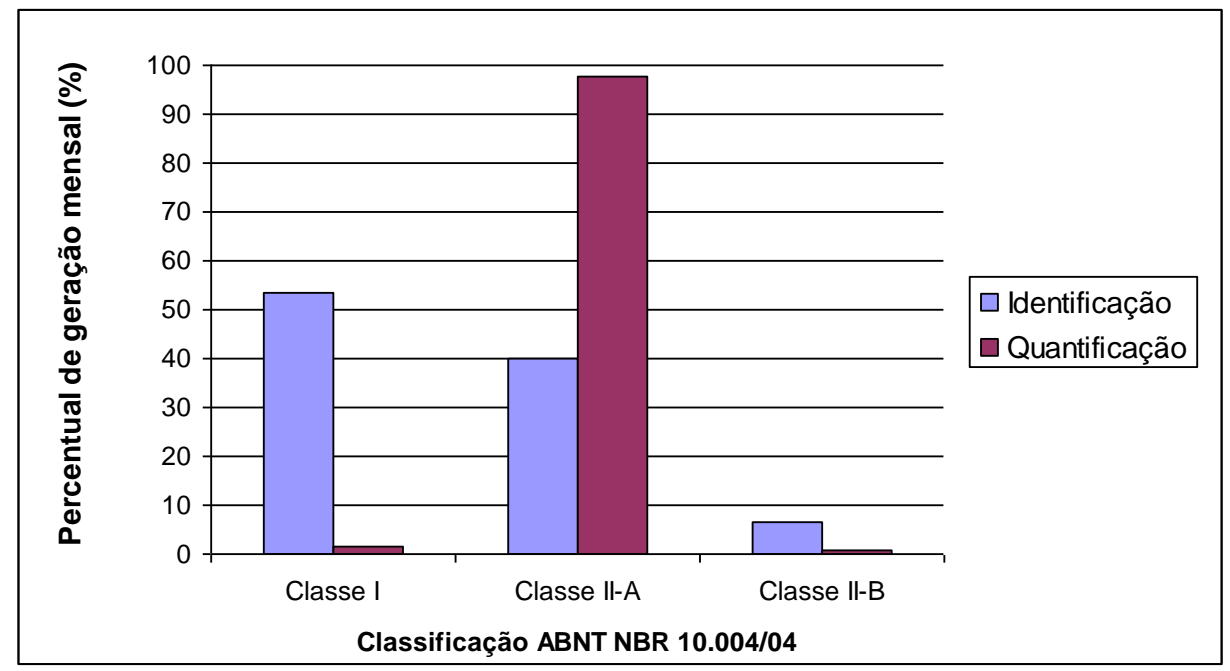

Fonte: Autoria própria (2014).

Por intermédio das massas encontradas, foram realizadas estimativas de relações dos resíduos sólidos gerados em cada ponto de geração da linha de produção de Piso (Quadro 2).

Essa relação orienta discussões que baseiam ações de minimização de resíduos em relação aos materiais de apoio ou máquinas existentes na linha de produção. Por exemplo, em se tratando de resíduos perigosos por unidade de geração, tem-se no terceiro item (Quadro 4), aproximadamente $0,7 \mathrm{Kg}$, o equivalente a $700 \mathrm{~g}$, onde por analogia mostra que para cada ponto de resíduos perigos são gerados aproximadamente duas "2" latas de querosene vazia, de conteúdo $900 \mathrm{ml}$, que equivale a uma massa de recipiente com $0,35 \mathrm{Kg}$ de resíduos gerados, o Quadro 3 demonstra a Relação dos resíduos sólidos gerados nos pontos de geração.

Quadro 3 - Relação dos resíduos sólidos gerados nos pontos de geração.

\begin{tabular}{|c|l|c|c|}
\hline Item & \multicolumn{1}{|c|}{ Indicador de resíduos } & Descrição & Total \\
\hline 1 & Quantidade Total & Absoluta & $485,34 \mathrm{Kg} / \mathrm{mês}$ \\
\hline 2 & $\begin{array}{l}\text { Quantidade de resíduos gerados nas } \\
\text { etapas produtivas }\end{array}$ & $\begin{array}{c}\text { Total de resíduo do } \\
\text { setor/quantidade de pontos ou } \\
\text { unidades de geração - UG }\end{array}$ & $\begin{array}{c}40,445 \mathrm{Kg} / \mathrm{UG} \\
\text { (total) }\end{array}$ \\
\hline 3 & Quantidade específica de resíduo nas & $\begin{array}{c}\text { Total de resíduo perigoso em } \\
\text { relação às unidades de } \\
\text { geração - UG }\end{array}$ & $\begin{array}{c}0,691818 \mathrm{Kg} / \mathrm{UG} \\
\text { (perigosos) }\end{array}$ \\
\cline { 3 - 4 } & etapas & $\begin{array}{c}\text { Total de resíduo não perigoso } \\
\text { em relação às unidades de } \\
\text { geração - UG }\end{array}$ & $\begin{array}{c}95,546 \mathrm{Kg} / \mathrm{UG} \\
\text { (não perigosos) }\end{array}$ \\
\hline
\end{tabular}

Fonte: Autoria própria (2014). 


\section{Conclusão}

O presente estudo analisou as características qualificados e quantificados dos resíduos sólidos gerados na linha de produção de piso na empresa Florestal Norte. Percebe-se que o setor estudado não apresenta uma grande diversidade qualitativa de resíduos industriais predominando resíduos com características comuns e de ampla utilização. Dentre estes foram identificados por meio da Norma ABNT NBR 10.004/2004 mais de 50\% de resíduos perigosos. No entanto isso não demonstra a realidade quantitativa de 1,57\% de resíduos perigosos do total de RSI pesquisados. Dentre estes, mais de $80 \%$ de resíduos são recicláveis e os Subgrupos Plástico PE e Papelão apresentam a maior contribuição na geração, respectivamente 34,5 \% e 21,9\%. Os Grupos Papel, Subgrupo Plástico PE, Grupo Metal, Subgrupo metal Contaminado, Fita Plástica PET, PP e Grupo Geral poderão ser destinados para reciclagem e para os dois últimos sua reutilização externa artesanal e reutilização interna em área de reflorestamento, respectivamente. Ou seja, menos de 3\% dos resíduos gerados mensalmente serão destinados ao aterro sanitário.

\section{Referências}

ABNT- Associação Brasileira de Normas Técnicas. Classificação dos resíduos sólidos. ABNT NBR 10.004, 2004.

ABNT- Associação Brasileira de Normas Técnicas. Procedimento para obtenção de extrato solubilizado de resíduos sólidos. ABNT NBR 10.006, 2004.

ABNT- Associação Brasileira de Normas Técnicas. Amostragem de resíduos sólidos. ABNT NBR 10.007, 2004.

ABNT- Associação Brasileira de Normas Técnicas. Armazenamento de resíduos classe II-não inertes e IIIinertes - Procedimento. ABNT NBR 11.174, 1990.

ABNT- Associação Brasileira de Normas Técnicas. Armazenamento de resíduos sólidos perigososProcedimento. ABNT NBR 12.235, 1992.

BRASIL, CONAMA - Conselho Nacional de Meio Ambiente . Resolução no 313, de 29 de outubro de 2002. Dispõe sobre o Inventário Nacional de Resíduos Sólidos Industriais.

BRASIL, CONAMA - Conselho Nacional de Meio Ambiente. Resolução no 275, de 25 de abril de 2001. Estabelece o código de cores para os diferentes tipos de resíduos.

BRASIL. Diretriz 1.310 de 03 de setembro de 2004. Estabelece a metodologia do sistema de manifesto de resíduos. Diário Oficial do Estado do Rio de Janeiro, 21 de setembro de 2004.

CPL, Consejo Nacional de Producción Limpia. Producción Limpia: Principios e Herramientas. 1. ed. Chile, 2005.

MONTEIRO, José Henrique Penido - Gestão Integrada de Resíduos Sólidos - Manual Gerenciamento integrado de Resíduos Sólidos... [et al.], Rio de Janeiro: IBAMA, 2001. 
NETA, Z. F. L. Curso: Resíduos Sólidos Industriais. SENAI/SETIND. Lauro de Freitas, 1992.

PEREIRA NETO, J. T. Gerenciamento do lixo urbano: aspetos técnicos e operacionais. Viçosa, MG: Ed. UFV, 2007.

PIMENTA, Handson Cláudio Dias; JUNIOR, Sergio Marques. Modelo de gerenciamento de resíduos sólidos: um estudo de caso na indústria de panificação em Natal-RN. Anais XXVI ENEGEP, Fortaleza, CE, 2006.

Disponível em: <http://www.abepro.org.br>. Acesso em: 3 de set. 2008.

ROCCA, A. C. C. Resíduos Sólidos Industriais - 2 ed. Ver Ampl. São Paulo. São Paulo: CETESB, 1993.

SBRT - Sistema Brasileiro de Respostas Técnicas, Resposta Técnica Tecpar. Densidade de Resíduos Sólidos Industriais, 2006. Disponível em:

<http://sbrtv1.ibict.br/upload/sbrt3599.pdf?PHPSESSID=5d046b168137459e0cdc363bcd34430a>. Acesso em 15 de junho de 2008.

SECRETARIA REGIONAL DO AMBIENTE. Resíduos Sólidos Urbanos - Quantificação e Caracterização Metodologia. Documento Técnico n ${ }^{\circ}$. Direção de Serviços de Resíduos e Produtos Químicos. Direção Geral da Qualidade do Ambiente, 1989.

\section{Abstract}

The need to conserve raw materials and resources, conserve energy and preserve the environment becomes crucial for efficient management of the solids from several actions, procedures and behaviors that can minimize the impacts associated with the production and disposal of garbage waste on the environment environment. To be considered as high risk to human health and the environment, greater attention to the waste generated by industries should (RI). The scope of this study was to analyze the qualitative and quantitative characteristics of solid waste generated in the production line in North Forest LTDA. At the end of the study, it was observed that less than $3 \%$ of the waste generated each month is for the landfill, this positive aspect, shows that these areas are suitable to house the disposal of waste systems, causing residual decreased (RI). In view of what has been mentioned, it is understood that about $97 \%$ of (RI) of this company are suitable for recycling.

Keywords: Solid waste, waste management, recycling.

\section{Dados dos autores:}

\section{Nome completo: Jakeline Oliveira Evangelista}

Filiação institucional: Universidade do Estado do Pará

Departamento:Departamento de engenharia ambiental

Função ou cargo ocupado:Monitora do Laboratório de Qualidade Ambiental

Endereço completo para correspondência:Universidade do Estado do Pará. Campus

Universitário de Marabá. Avenida Hiléia s/n - Acrópole do Incra. Bairro Amapá. Marabá-PA.

Cep: 68.503-120.

Telefones para contato: 9499243-7233/ 9498152-6595

e-mail: jaakeline95@hotmail.com/jakelineolievan@gmail.com 
Nome completo: Glauber Epifanio Loureiro

Filiação institucional:Universidade do Estado do Pará

Departamento: Departamento de engenharia ambiental

Função ou cargo ocupado: Prof. Assistente

Endereço completo para correspondência:Universidade do Estado do Pará. Campus

Universitário de Marabá. Avenida Hiléia s/n - Acrópole do Incra. Bairro Amapá. Marabá-PA.

Cep: 68.503-120.

Telefones para contato: $9418152-2232$

e-mail:epfanio@uepa.br

\section{Nome completo: Jonathas Castanha Bezerra}

Filiação institucional: Universidade do Estado do Pará

Departamento: Departamento de Engenharia ambiental

Função ou cargo ocupado:Graduado em Engenharia ambiental.

Endereço completo para correspondência: Universidade do Estado do Pará. Centro de

Ciências Naturais e Tecnologia. Trav. Enéas Pinheiro, nº 2626. Bairro: Marco. Belém-PA Cep: 66095-100

Telefones para contato: 9198515-3615

e-mail: jonathascastanha@yahoo.com.br

Submetido em: 10-04-2015

Aceito em: 14-09-2015 